\title{
The Driver of Development and Transformation of Global Oil and Gas Business in Digital Economy's Conditions
}

\author{
D.R. Peskova ${ }^{1}, Y u . V$. Khodkovskaya $^{2}$ and M.A. Nazarov ${ }^{3, *}$ \\ "Corresponding author: good_mn@mail.ru \\ ${ }^{1}$ Financial University under the Government of Russian Federation, Moscow, Russia \\ ${ }^{2}$ Ufa State Technological Petroleum University, Ufa, Russia \\ ${ }^{3}$ Samara State University of Economics, Samara, Russia
}

\begin{abstract}
The digitalization of the oil and gas sector is the strong driver for Russian economy increasing efficiency. The main purpose of this study is to find out the main digitalization development trends of the oil and gas sector and the growth barriers and effects in Russian oil and gas industry in modern digital economy conditions. The results of this study show options of digital technology using in oil and gas sector in Russia.
\end{abstract}

Keywords: digitalization, digital transformations economy, oil and gas business.

\section{Introduction}

Industrial relations are being transformed by modern information processing and computer algorithms. This leads to the creation of new models of interaction between agents and systems in economic processes, cyber-physical devices, etc. Russian oil and gas industry faces the task of rethinking business models used in practice because of price instability. Oil and gas service greatly lags behind other industry - the leaders of digitalization. There are such industries as telecommunications industry (PAO "Rostelecom", PAO "MTS"), banking industry (PAO Sberbank), information technology (OOO "Mail.ru", "The 1C" company) and nuclear energy (Rosatom).

Russian technology and equipment used in oil and gas industry is materially upgraded. However, Russian geological exploration, oil and gas production and transportation have the clear lag in comparison with abroad robotics and sensor technology components level. According to The International Networked Readiness Index 2016 Russian Federation ranks 41 and gives way to Finland, Sweden, USA, Japan and other countries. Also according to I-DESI showing digital economy development in the country, Russia greatly legs far behind EU, Canada, Australia and etc. [1]. Nevertheless, the state and business are interested in the advantages from the digital technology. Many Russian oil and gas companies try to use modern digital ways of working (digital design, telecommunication equipment and etc.). So the industry searches the way to return the profit margin and digital technologies can help with it giving the opportunity to greatly increase the working profitability.

\section{Problem Statement}

The analysis of modern scientific views on the digital economy established that in terms of economic entities, digital development of production and logistics processes is seen by the creation of multi-level information and digital platforms and operators that allow to solve various economic problems (neo-industrialization, regulation and planning, development of science and technology, personnel management), mass conversion of industrial and post-industrial technologies to digital, creation and widespread use of cloud technologies, cognitive service, artificial intelligence, big data processing, etc. [2]. Thus, the intensive digital technologies usage leads to the fast industry development but also the financial sector, construction, transport, trade, communications, health, science, education and other industries.

The explosive nature of digital technologies was noted by K. Schwab, showing the modern economy development depends on the digital transformation level. "New technologies and social groups and the interaction that they provide allow almost anyone to influence the situation and at the same time in ways it would be impossible few years ago" [3].

The most industries are actively introducing digitalization products or forming the preconditions for their implementation because of the analysis of modern views of scientists and practitioners on the effects and barriers of digital transformation of the world economy. According to the A.D. Little [4] the global digitalization is the modern world economy trend, however, a lot of companies either don't know or ignore the digital impact potential threats on their business. O. Kitova and S. Bruskin point out: "despite the fact that digital approaches to management are in demand, many companies are not ready for their implementation" [5]. Some scientists, describing the digital technology management in oil companies current practice, point to the lack of rapid digitalization processes implementation [6]. According to experts, digital transformation affects all areas of business (current, investment, financial), improving the business environment of companies. 


\section{Research Questions}

The research questions of this paper include: to explore the current state of digital economy of Russian oil\&gas companies, to identify the obstacles for more effective digitalization of the industry and to understand the perspectives of digital economy development. The study shows options of digital technology using in oil and gas sector in Russia.

\section{Purpose of the Study}

The digitalizing of oil and gas industry is the priority thing for Russia. It is due to technology and structure transformation of business processes. It means the industry equipment changing and analytical system implementation. So the system such deeply integration technologies with business processes can make the most profitable production.

Such facts as: the significant lag of Russian companies' automatization and digitalization products (IBM, Microsoft, SAP, Oracle and etc.) of international leaders and high risks due to "digital slavery" problem - identified need for development of quality and innovation products which can quickly form the competitive advantages of Russian companies.

The purposes of this study are the following: a) to describe the main digitalization development trends of the oil and gas sector abroad; b) to analyze the positive experience of digital technology realization in the oil and gas companies' management; c) to find the growth barriers and effects in Russian oil and gas industry in modern digital economy conditions.

\section{Research Methods}

There are scientific knowledge methods for solving the research problem and gaining the aim with the main ways: analyze and synthesis, scientific generalization. The research information base consists of annual financial statements of foreign and Russian oil companies, analytical reviews of digital fields using in oil and gas industry, information from analytical research centers (CERA, Accenture, Deloitte, Pwc), legislative and regulatory acts of the Russian Federation, scientific articles of foreign and Russian authors which were published on the topic of creation and using digital technologies during searching, exploration and creation oil and gas fields.

\section{Findings}

Cambridge Energy Research Associates (CERA) evaluates the potential for field digitization at 125 billion barrels. So this can be increase the return of open fields if work organization is improved in future. According to the estimation of experts, oilmen can increase the oil recovery factor by $2-7 \%$ and reduce operating costs by a quarter because of complex use of IT-technologies. Digital technologies compensate the depleted deposits oil production volume, improving efficiency of geological exploration and implementation speed of enhanced oil recovery methods and technologies for development of hard-to-recover reserves.

According to International Energy Agency in the sphere of digitalization of the oil and gas industry in 2017, digital technologies can reduce production costs by $20 \%$. This savings can be used as operational excellence (e.g. more efficient maintenance and operation of assets), as supply chain, as the artificial intelligence and integrated platforms using. On the base of the research by Raunholt and others [7] the improvement of business efficiency from digitization vary from 20 to $12 \%$, what makes it a very perspective source of development.

The analysis of digitalizing elements applications in the world practice show that international exploration and production companies identify the strategic business value of technologies based on the "Internet of things", cloud computing and artificial intelligence. The digitalization elements are the most widely used in 3D seismic technologies, unmanned oil and gas installations of the North Sea mainly by the companies of Holland and Denmark.

The digital innovations trend increases in the oil and gas industry because companies are more focused on reducing costs and work efficiency improving, during it is relatively low oil prices. A number of large oil and gas companies have already been quite far and successfully using digital technologies.

The British transnational company «British Petroleum» expanded its capabilities by creating own digital workforce and launching digital leadership training camps. The company encourages its employees to develop applications stored on common platforms to improve workflows. It also created a "data lake" where billions of data records from global operations are provided to managers entire the firm when making management decisions.

Italian oil and gas company "Eni" has developed its own supercomputer HPC4, which is used to process data on oil and gas tanks. This technology saves time and money allowing analyze exploration prospects in weeks not in months. The drilling in the right place can give significant savings given the fact that drilling exploration wells can cost hundreds of millions of dollars [8].

Statoil ASA, the largest oil and gas company in Norway, uses a centralized and integrated digital improvement program that can form a comprehensive roadmap for digitization until 2020. The company invested about 2 billion 
NOK in digital and new technologies implemented in the center of excellence. The aim of Statoil ASA is to greatly increase the data using, analytics and robotics to improve safety, reduce carbon footprint and improve business profitability [9].

On the other hand, there are small oil and gas exploration and production (E\&P) companies are just beginning to implement digital transformation. As a first step, pilot projects are typically created to identify the key digital opportunities needed to be implemented. In these ways, interest in digital transformation is associated with the probability of additional business revenues and the influx of new market participants into the industry, the development of a competitive environment, and as a consequence an increase in the level of risk. Given the increasing sensitivity of production and logistics operations in the oil and gas industry, the problems associated with the geographical distribution of assets, inherited assets, which, as a rule, have a long-term decline in production, despite the introduction of digital technologies.

Due to the fact that production of raw materials is depleted in most of the developed fields, therefore, it's necessary to digitalize new fields and it requires large investment in the industry. So Russian oil and gas industry technology digitalization transition is complicated and stretched over time.

For a quantitative assessment of the impact of open fields on the oil and gas industry and society as a whole, the criteria for the efficiency of digitalization have been determined (Fig.1).

One of the factors of saving in using digital technologies in the fields is remote control and proactive operations, which lead to fewer accidents and rapid elimination of well breakdowns. It helps to reduce the downtime of the well and reduce the cost of lifting work and work to restart wells. In addition, the automation of processes in oil production allows increasing oil recovery by optimizing the oil recovery modes.

The main questions can be highlighted and solved by "the smart fields" because of global experience of digital technologies has used ones in the fields about 10 years.

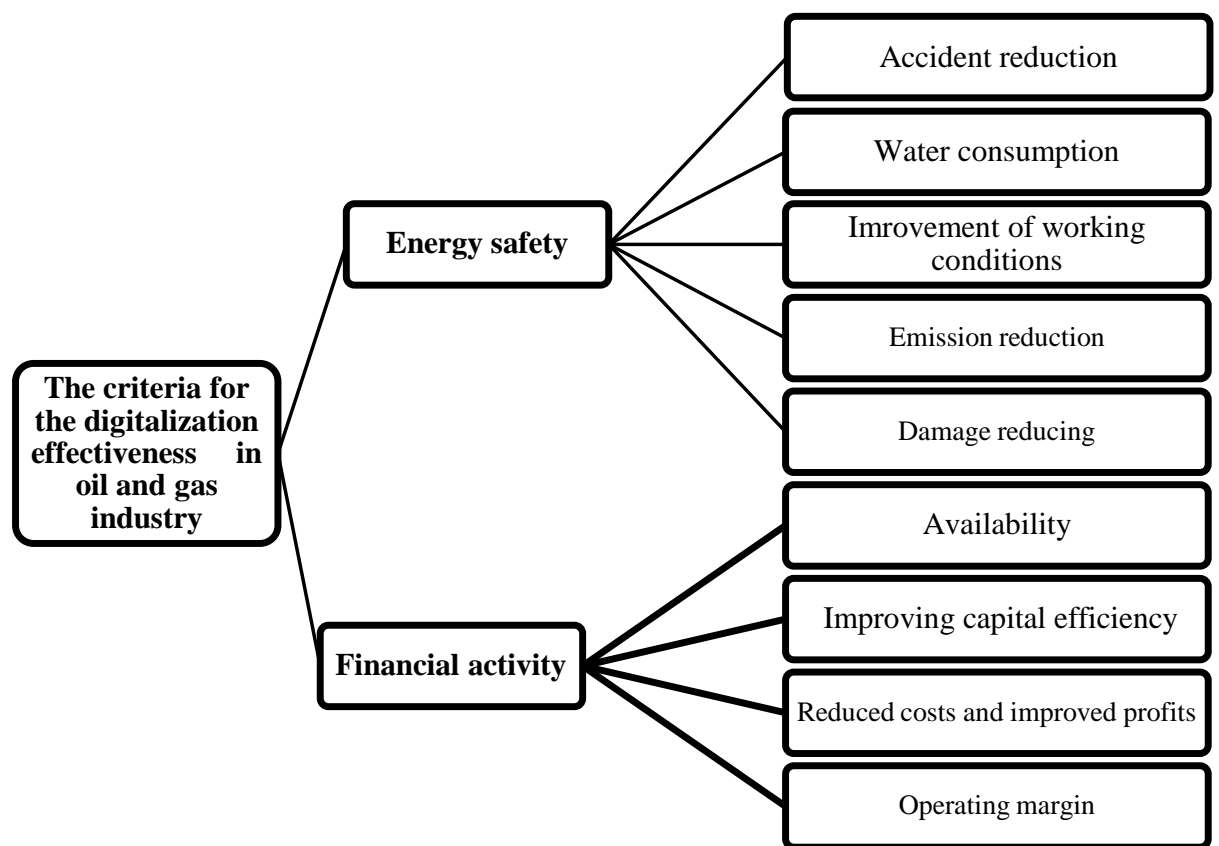

Figure 1. The criteria for the digitalization effectiveness in oil and gas industry (Source: compiled by the authors)

For example, Russia should pay attention to Norway oil companies' experience. These ones have been using Real Time Reservoir Management (RTRM) for several years. The inventory management question has been moved into realtime mode by the RTRM technology integrations in the modified business processes. Based on the traditional economic analysis of changes RTRM complex implements new approaches and new technological developments in the companies and the region resource management field. So, the resulting added value depends on faster resources reproduction, technological solutions improvement in drilling and field development and increase of capital investment efficiency. Several researchers studied usage of the digital technologies in oil and gas complex of Russia [8, 10].

The overall the expectations of experts about oil and gas sector digitalization are satisfactory. But the transport management improvement and increase in the productivity of the field are more important things for the development. Therefore, there is more time needed to automate field operations and the mining process because of the low adaptability of the equipment to digitalization.

Experts note that the digital technologies benefits have some risks: low network bandwidth; lack of necessary qualifications; organizational barriers; cyber-security in the country; funding constraints.

The funding constraints and cyber-security in the country are main obstacles to the oil and gas industry digitalization. It should be noticed, the USA budget for cyber-security amounted to $\$ 19$ billion in 2017, global budget is more than $\$ 80$ billion. Russian budget for cyber-security is more than 55 billion rubles. This is not enough to reduce the digital technologies introduction risks. 
There is state support in two ways needed to remove barriers. The first one is legislative support - the legal framework adaptation and companies of implementation digital technologies legal protection increasing. The second thing is the creation enabling environment for companies following the way of industry digitalization.

Despite the existing barriers, information technology unites business, states, population. Companies create its own business-networks for providers, customers, and internal systems inclusion. The result of this activity is the increasing global internet-trade. There will be endless possibilities environment if to add to this the "Internet of things" growth and about 45 billion connections between devices.

Russian oil and gas companies need to take into account the main obstacles to business digitalization and the following recommendations for future digital technologies promotion:

1. Digitized and controlled. Analog objects generate digital signals that can be measured, tracked and analyzed to better decision-making in the digital economy. Digitized assets have been limited to expensive equipment while the oil and gas industry has outpaced the digitization process for over 30 years. However, lower sensor technology costs allow operators to process more data in the field. For example, companies can connect multiple oil fields to improve forecast accuracy and profitability.

2. Connectivity. Assets, suppliers, employees and stakeholders are interlinked through wireless connectivity. This enables economic agents to make data-based decisions, increasing security, efficiency and visibility in the company. Oil and gas companies eliminate unexpected failures, improve asset integrity and increase uptime by connecting remote pipelines to each other and providing predictive maintenance.

3. The digital economy works on sharing. Purchasing the required quantity reduces inventory costs, while purchasing the use as a service allows companies to pay only for the time used and the cost received. Oil and gas companies can automate tank replenishment, use best-buy scenarios and plan optimized truck routes for delivery to service stations.

4. Personalization. The another digital economy characteristic is customer personalization. Personalization means customers get customized products and experiences from their favorite brands whenever and wherever they want.

5. Spontaneity. The digital economy also allows oil and gas companies to bypass intermediaries, eliminate unnecessary intermediary channels and create a more direct relationship between buyer and seller. The simplified ecosystem has less friction and reduces the barrier to entry for players in another part of the value chain. Monitoring remote services is a good example of more direct operations. The use of remote intelligence to track, monitor, manage, report and address asset issues throughout the service life cycle eliminates the need for field staff [10].

\section{Conclusion}

The digitalization has a positive effect on the development of the industry and capitalization growth of the oil and gas companies. But it should be taken into account the digitalization makes significant changes in territory ecosystems, violates traditional way of cost creation and redefines the roles. New business models allow companies to grow faster and make non-competitiveness of others in the market.

Obviously every digital solution in an oil and gas company will differ depending on their position in the industry, ambitions and opportunities. Moreover, digital leadership isn't always the best strategy for a company and it can be expensive. However, digitalization can reduce costs by improving the quality of business processes while low oil and gas prices limit companies ' investment opportunities. Each oil and gas company should develop a strategic plan for how digital technologies will be used to gain a competitive advantage over the next years. All these plans should include initiatives offering short-term benefits and opportunities to create long-term competitive advantages.

Thus, the recommendations for further digital technologies promotion are associated with a clear understanding of the digital technologies possibilities, leadership in execution, cooperation forms improvement with partners, development and expansion of dialogue between the business process participants.

\section{References}

1. S. Baller, S. Dutta, B. Lanvin (Ed.s), The Global Information Technology Report 2016. Innovating in the digital economy. URL: http://www3.weforum.org/docs/GITR2016/WEF_GITR_Full_Report.pdf Accessed 21.01.2019 (2016).

2. V. Kulkov, Digital economy: hopes and illusions. Philosophy of Economy, 5, 145-156 (2017).

3. K. Schwab, The fourth industrial revolution. Moscow: Eksmo (2016).

4. A. Little, Digital transformation - How to become digital leader. Study results - Overview. URL: https://www.wko.at/branchen/information-consulting/unternehmensberatung-buchhaltunginformationstechnologie/Digital-Transformation-Study-Overview---Teaser.pdf Accessed 21.01.2019 (2015)

5. O. Kitova, S. Bruskin, Digital transformation of business. Digital Economy, 1, 20-25 [in Rus.] (2018).

6. R. Xinquan, G. Yulong, C. Shilong, Innovations and practices of oil field digital management. In J. Xiong (Ed.), Advanced Materials and Information Technology Processing: Proceedings of International Conference (AMITP 
2011), Guangzhou: Thomson Reuters CPCI-S, 264-269. DOI: 10.4028/www.scientific.net/AMR.271-273.264 (2011).

7. L. Raunholt, R. Servodio, A. Maliardi, S. Torvund, First implementation of robot technology for the drill floor. Offshore Mediterranean Conference. Italy. URL: https://www.onepetro.org/conference-paper/OMC-2017-596 (2017).

8. A. Dmitrievsky, N. Eremin, Big geodata in the digital oil and gas ecosystem. Energy politics, 2, 31-39. [in Rus.] (2018).

9. T. Kohler, K. Matzler, J. Fueller, Avatarbased innovation: Using virtual worlds for real-world innovation. Technovation. 29, 395-407. DOI: 10.1016/j.technovation.2008.11.004 (2009).

10. A. Ivlev, N. Eremin, Petrorobotics: Robotic drilling systems. Drilling and Oil, 2, 8-12. [in Rus.] (2018). 